\title{
Kinetics and Mechanistic Study of the Ruthenium(III) Catalysed Oxidative Decarboxylation of L-Proline by Alkaline Heptavalent Manganese (Stopped flow technique)
}

\author{
R.S.SHETTAR, M.I.HIREMATH and S.T. NANDIBEWOOR* \\ P.G. Department of Studies in Chemistry, \\ Karnatak University, \\ Dharwad-580003, India.
}

\begin{abstract}
The kinetics of ruthenium(III) catalysed oxidation of L-Proline by permanganate in alkaline medium at a constant ionic strength has been studied spectrophotometrically using a rapid kinetic accessory. The reaction between permanganate and L-Proline in alkaline medium exhibits 2:1 stoichiometry $\left(\mathrm{KMnO}_{4}\right.$ : L-Proline). The reaction shows first order dependence on [permanganate] and [ruthenium(III)] and apparent less than unit order dependence each in L-Proline and alkali concentrations. Reaction rate increases with increase in ionic strength and decrease in solvent polarity of the medium. Initial addition of reaction products did not affect the rate significantly. A mechanism involving the formation of a complex between catalyst and substrate has been proposed. The activation parameters were computed with respect to the slow step of the mechanism and discussed.
\end{abstract}

Key words: Kinetics; Potassium permanganate Ruthenium; Oxidation; L-proline

\section{Introduction}

Potassium permanganate is widely used as an oxidising agent in synthetic as well as in analytical chemistry and also as a disinfectant. The reactions with permanganate are governed by $\mathrm{pH}$ of the medium. Among six oxidation states of manganese from $2+$ to $7+$, permanganate, $\mathrm{Mn}(\mathrm{VII})$ is the most potent oxidation state in acid as well as in alkaline medium.

The chemistry of manganese due to multistep redox reactions is an important source of information. The manganese intermediates are relatively easy to identify when they have sufficiently long life times and oxidation states of the intermediates permit useful conclusions as to the possible reaction mechanism. The oxidation by permanganate ion finds extensive applications in organic syntheses ${ }^{1-3}$ especially since the advent of phase transfer catalysis ${ }^{3}$ which permits the use of solvents 
such as methylene chloride and benzene. Kinetic studies are important sources of mechanistic information on the reactions, as demonstrated by the results referring to unsaturated acids both in aqueous ${ }^{1}$ and non-aqueous media ${ }^{4}$. Furthermore, the mechanism by which the multivalent oxidant oxidises a substrate depends not only on the substrate but also on the medium ${ }^{5}$ used for the study. In strongly alkaline medium, the stable reduction product ${ }^{6}$ of permanganate ion is manganate ion, $\mathrm{MnO}_{4}{ }^{2-}$. No mechanistic information is available to distinguish between a direct one-electron reduction to $\mathrm{Mn}$ (VI) (Scheme 1) and a mechanism, in which a hypomanganate is formed in a two-electron reduction followed by a rapid oxidation of the hypomanganate ion (Scheme 2).

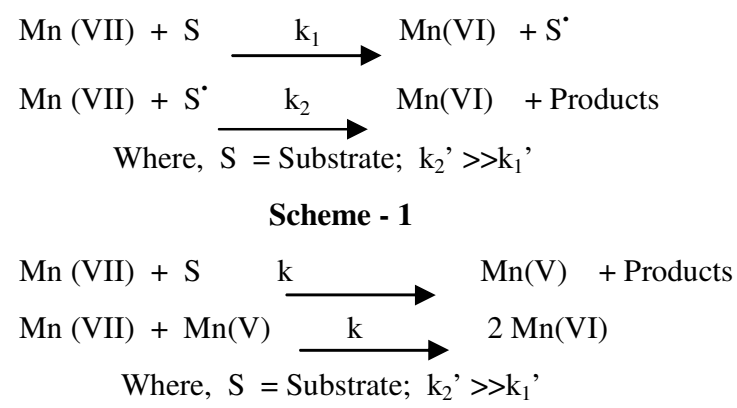

Scheme - 2

L-Proline is one of the amino acids, which occurs in relatively high concentrations in plant tissues. Its role in metabolism is crucial and also finds extensive applications in pharmaceuticals and medicines. Enzymatic dehydrogenation of $\alpha$-amino acids by flavoenzymes has attracted considerable attention in recent years. Infact a precise understanding of the mechanism of such biological redox reactions ${ }^{7}$ is important as it helps in the synthesis of specific reaction products. Many attempts were made to mimic flavin-catalaysed oxidations of $\alpha$-amino acids ${ }^{8}$ to the corresponding $\alpha$-keto acids by non-enzymatic means. These studies were found to yield the corresponding noraldehyde by oxidative decarboxylation of $\alpha$-amino acids ${ }^{9}$. The kinetic investigation of the oxdation of $\alpha$-amino acids by a variety of oxidants has been carried out under different experimental conditions. In many cases it was reported that amino acids undergo oxidative decarboxylation. Jayaprakash rao ${ }^{10}$ et al suggested that the oxidation of $\alpha$-amino acids by two electron oxidant such as diperiodatoargentate (III) in alkaline medium involves two electron transfer from the amino acid to the oxidant to give imino acid intermediate which subsequently undergoes hydrolysis to yield keto acids. One electron oxidants such as ceric sulphate ${ }^{11}$, cause decarboxylation during the oxidation of $\alpha$-amino acids. Hexacyanoferrate(III ${ }^{12}$, a potential one-electron oxidant is reported to oxidize $\alpha$-amino acids to corresponding $\alpha$-keto acids. The study of amino acids become important because of their biological significance and selectivity towards the oxidants. Similarly L-Proline gave different products with different oxidants ${ }^{13}$.

Ruthenium(III) is known to be an efficient catalyst in several redox reactions particularly in alkaline medium ${ }^{14}$. The mechanism of catalysis can be quite complicated due to the formation of different intermediate complexes, free radicals and different oxidation states of ruthenium. The kinetics of fast reactions between ruthenate(VII), $\mathrm{RuO}_{4}{ }^{-}$, and manganate(VI), i.e. $\mathrm{MnO}_{4}{ }^{2-}$ have been studied ${ }^{15}$ and the reaction is presumed to proceed via an outer-sphere mechanism. The rapid exchange between $\mathrm{MnO}_{4}{ }^{2-}$ and $\mathrm{MnO}_{4}^{-}$has been studied in detail by a variety of techniques ${ }^{16}$. The uncatalysed reaction between L-Proline and permanganate in alkaline medium has been studied previously ${ }^{17}$. A micro amount of ruthenium (III) is sufficient to catalyse the reaction in alkaline medium and a variety of mechanisms are possible. Thus, in order to explore the mechanism of oxidation by permanganate ion in aqueous alkaline medium and to check the selectivity of L-Proline towards permanganate in catalysed system, we have selected ruthenium (III) as a catalyst. The present study deals with the title 
reaction to investigate the redox chemistry of permanganate, ruthenium (III) and L-Proline in such media and to arrive at a plausible mechanism.

\section{Experimental}

Since the initial reaction was too fast to be monitored by the usual methods, kinetic measurements were performed on a Hitachi 150-20 spectrophotometer connected to a rapid kinetic accessory (HITECH SFA-12).

\section{Materials: Chemicals}

Stock solution of L-Proline (Sisco-Chem.Ltd) was prepared by dissolving the appropriate amount of sample in doubly distilled water. The solution of potassium permanganate (BDH) was prepared and standardized against oxalic acid ${ }^{18}$. Potassium manganate solution was prepared as described by Carrington and Symons ${ }^{19}$. The solution was standardized by measuring the absorbance on a Hitachi $150-20$ spectrophotometer with a $1 \mathrm{~cm}$ quartz cell at $608 \mathrm{~nm}\left(\varepsilon=1530 \pm 20 \mathrm{dm}^{3} \mathrm{~mol}^{-1} \mathrm{~cm}^{-1}\right)$. The ruthenium(III) solution was prepared by dissolving a known weight of $\mathrm{RuCl}_{3}$ (s.d.fine-chem) in 0.20 mol dm${ }^{-3} \mathrm{HCl}$. Mercury was added to the ruthenium(III) $\mathrm{dm}^{3} \mathrm{~mol}^{-1} \mathrm{~cm}^{-1}$ solution to reduce any $\mathrm{Ru}$ (IV) formed during the preparation of ruthenium (III) stock solution and was kept for a day. The ruthenium (III) concentration was assayed ${ }^{20}$ by EDTA titration.

All other reagents were of analytical grade and their solutions were prepared by dissolving the requisite amounts of the samples in doubly distilled water. $\mathrm{NaOH}$ and $\mathrm{NaClO}_{4}$ were used to provide the required alkalinity and to maintain the ionic strength respectively.

Kinetic procedure:

All kinetic measurements were performed under pseudo-first order conditions with [L-Proline] excess over $\left[\mathrm{MnO}_{4}^{-}\right]$at a constant ionic strength of $0.20 \mathrm{~mol} \mathrm{dm}{ }^{-3}$. The reaction was initiated by mixing previously thermostatted solutions of $\mathrm{MnO}_{4}^{-}$, and L-Proline which also contained the necessary quantities of $\mathrm{Ru}(\mathrm{III}), \mathrm{NaOH}$ and $\mathrm{NaClO}_{4}$ to maintain the required alkalinity and ionic strength respectively. The temperature was uniformly maintained at $25 \pm 0.1^{\circ} \mathrm{C}$. The course of reaction was followed by monitoring the decrease in the absorbance of $\mathrm{MnO}_{4}{ }^{-}$in a $1 \mathrm{~cm}$ quartz cell of a Hitachi model 150-20 Spectrophotometer at its absorption maximum of $526 \mathrm{~nm}$ as a function of time. The application of Beer's law to permanganate at $526 \mathrm{~nm}$ had been verified, giving $\varepsilon=2083 \pm 50 \mathrm{dm}^{3} \mathrm{~mol}^{-1} \mathrm{~cm}^{-1}$ (Literature $\left.\varepsilon=2200 \mathrm{dm}^{3} \mathrm{~mol}^{-1} \mathrm{~cm}^{-1}\right){ }^{10}$. The first order rate constants, $\mathrm{k}_{\mathrm{obs}}$ were evaluated by plots of $\log \left(\mathrm{A}_{\mathrm{t}^{-}}\right.$ $A_{\infty}$ ) versus time(Fig.1), where $A_{t}$ and $A_{\infty}$ refers to absorbencies at time $t$ and $\infty$ respectively. The first order plots in almost all cases were linear to $80 \%$ completion of the reaction and $\mathrm{k}_{\text {obs }}$ were reproducible within $\pm 5 \%$.During the course of measurements, the solution changed from violet to blue and then to green. The spectrum of the green solution was identical to that of $\mathrm{MnO}_{4}{ }^{2-}$. It is probable that the blue colour originated from the violet of permanganate and the green from the manganate, excluding the accumulation of hypomanganate. It is also evident from the Fig. 2 that the absorbance of permanganate decreases at $526 \mathrm{~nm}$ whereas the absorbance of manganate increases at $608 \mathrm{~nm}$.

The effect of dissolved oxygen on the rate of reaction was checked by preparing the reaction mixture and following the reaction in an atmosphere of nitrogen. No significant difference between the results obtained under the nitrogen and in the presence of air was observed. In view of the ubiquitous contamination of basic solutions by carbonate, the effect of carbonate on the reaction was also studied. Added carbonate had no effect on the reaction rate. However, fresh solutions were used when conducting the experiments.

A regression analysis of experimental data in order to obtain the regression coefficient, $r$ and standard deviation, s of plots from the regression line was performed with a Pentium - IV personal computer.

\section{Results}

Stoichiometry and product analysis

The reaction mixtures containing an excess permanganate concentration over L-Proline, constant [Ru (III)], $0.10 \mathrm{~mol} \mathrm{dm}^{-3} \mathrm{NaOH}$ and adjusted ionic strength of $0.20 \mathrm{~mol} \mathrm{dm}^{-3}$ was allowed to react for 2 hours in an inert atmosphere at $25 \pm 0.1^{\circ} \mathrm{C}$. After completion of the reaction, solid KI was added 
followed by acidification by $10 \% \mathrm{H}_{2} \mathrm{SO}_{4}$. The remaining $\mathrm{MnO}_{4}^{-}$was then determined by spectrophotometrically. The results indicated that two moles of $\mathrm{MnO}_{4}{ }^{-}$consumed by one mole of $\mathrm{L}-$ Proline as given by equation .

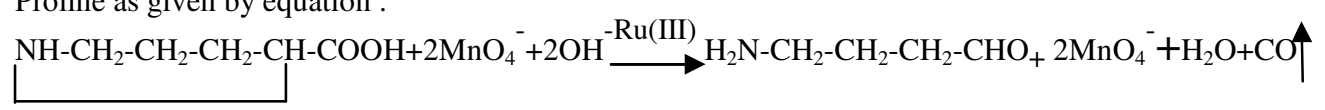

The main reaction products were identified as the aminobutaraldehyde by spot test ${ }^{21}$ for amine and aldehyde groups. The product, aminobutaraldehyde was also confirmed by IR spectroscopy ${ }^{22}$ which showed bands at $3444 \mathrm{~cm}^{-1}$ for NH stretching, $1773 \mathrm{~cm}^{-1}$ for aldehydic $>\mathrm{CO}$ stretching and $2956 \mathrm{~cm}^{-1}$, for aldehydic $-\mathrm{CH}$ stretching respectively. The only organic product obtained in the oxidation is aminobutaraldehyde,which is further confirmed by single spot in TLC. Test for the corresponding acid was negative. It was further observed that the aldehyde does not undergo further oxidation under prevailing kinetic conditions.

\section{Reaction orders}

The reaction orders were determined from the slopes of $\log \mathrm{k}_{\mathrm{obs}}$ versus $\log$ concentration plots by varying the concentration of reductant, catalyst and alkali in each, while keeping others constant. The oxidant, potassium permanganate at a constant concentration of L-Proline, $\mathrm{Ru}(\mathrm{III})$ and alkali, while maintaining constant ionic strength of $0.20 \mathrm{~mol} \mathrm{dm}^{-3}$, concentration was varied in the range of $5.0 \times 10^{-}$ ${ }^{5}$ to $5.0 \times 10^{-4} \mathrm{~mol} \mathrm{dm}{ }^{-3}$. The linearity of plots of $\log \left(\mathrm{A}_{\mathrm{t}}-\mathrm{A}_{\infty}\right)$ versus time indicates the order in $\left[\mathrm{MnO}_{4}{ }^{-}\right]$ as unity (Table1). This was also confirmed by varying $\left[\mathrm{MnO}_{4}{ }^{-}\right]$which did not show any change in pseudo-first order constants $\mathrm{k}_{\mathrm{obs}}$ values as shown in Table 1 . The substrate L-Proline was varied in the range of $5.0 \times 10^{-4}$ to $5.0 \times 10^{-3} \mathrm{~mol} \mathrm{dm}^{-3}$ at $25^{\circ} \mathrm{C}$; the order with respect to [L-Proline] was found to be less than unity. The catalyst $\mathrm{Ru}(\mathrm{III})$ was varied in the range of $5.0 \times 10^{-7}$ to $1.0 \times 10^{-6} \mathrm{~mol} \mathrm{dm}^{-3}$ at $25^{\circ} \mathrm{C}$; the order with respect to $[\mathrm{Ru}(\mathrm{III})]$ was found to be unity. The effect of alkali on the reaction was studied at constant concentrations of L-Proline, $\mathrm{Ru}$ (III) and potassium permanganate and at a constant ionic strength of $0.20 \mathrm{~mol} \mathrm{dm}^{-3}$ at $25^{\circ} \mathrm{C}$. The rate constant increased with the increase in [alkali], indicating an apparent less than unit order dependence on [alkali] as given in Table1.

Effect of initially added products:

The externally added products such as manganate, ammonium hydroxide and aldehyde did not show any significant effect on the rate of the reaction.

Effect of relative permittivity and ionic strength

The effect of dielectric constant $\left(\epsilon_{\mathrm{T}}\right)$ effect was studied by varying the t-butanol water content in the reaction mixture with all other conditions being maintain constant. Attempts to measure the dielectric constants were not successful. However, they were computed from the values of pure liquids ${ }^{23}$. The solvent did not react with the oxidant under the experimental conditions. The rate constants, $\mathrm{k}_{\mathrm{obs}}$ increased with decrease in the dielectric constant of the medium. The plot of $\log \mathrm{k}_{\mathrm{obs}}$ versus $1 / \epsilon_{\mathrm{T}}$ was linear with positive slope $(r>0.9983, \mathrm{~s} \leq 0.0341)$. The effect of ionic strength was studied by varying the sodium perchlorate concentration from 0.2 to $2.0 \mathrm{~mol} \mathrm{dm}^{-3}$ at constant concentrations of permanganate, L-Proline, ruthenium (III) and alkali. The rate constant increased with increasing concentration of $\mathrm{NaClO}_{4}$; the plot of $\log \mathrm{k}_{\mathrm{C}} v s \mathrm{I}^{1 / 2}$ was linear $(\mathrm{r}>0.9978, \mathrm{~S} \leq 0.018)$ with a positive.

\section{Test for free radicals:}

The reaction mixture was mixed with acrylonitrile monomer and kept for 2 hours in an inert atmosphere. On diluting with methanol a white precipitate was formed, indicating the intervention of free radicals in the reaction. The blank experiments of either $\mathrm{MnO}_{4}{ }^{-}$or L-Proline alone with acrylonitrile did not induce polymerization under the same conditions as those induced with reaction mixtures. Initially added acrylonitrile decreases the rate indicating the free radical intervention which is the case in earlier work ${ }^{24}$.

\section{Effect of temperature:}

The rate of the reaction was measured at four different temperatures with varying $\left[\mathrm{OH}^{-}\right]$, keeping other conditions constant. The rate was found to increase with increase in temperature. The rate constants, $\mathrm{k}$ 
of the slow step of scheme 3 were obtained from the intercept of the plots of $[\mathrm{Ru}(\mathrm{III})] / \mathrm{k}_{\mathrm{obs}}$ versus $1 /\left[\mathrm{OH}^{-}\right]$for different temperatures. The values of $\mathrm{kx} 10^{-4}\left(\mathrm{dm}^{3} \mathrm{~mol}^{-1} \mathrm{~s}^{-1}\right)$ at temperatures, $298 \mathrm{~K}, 303 \mathrm{~K}$, $308 \mathrm{~K}$, and $313 \mathrm{~K}$ are $6.5,7.2,8.0$ and 9.6 respectively. The energy of activation corresponding to these constants were evaluated from the plot of $\log \mathrm{k}$ versus $1 / \mathrm{T}(\mathrm{r} \geq 0.945 \& \mathrm{~s} \leq 0.0062)$ and other activation parameters are calculated. The values of Ea, $\Delta \mathrm{H}^{\#}, \Delta \mathrm{S}^{\#}$, and $\Delta \mathrm{G}^{\#}$ are $19.8 \pm 1.0,17.5 \pm 1.5\left(\mathrm{~kJ} \mathrm{~mol}^{-1}\right)$, $-18.3 \pm 1.5\left(\mathrm{~J} \mathrm{~K}^{-1} \mathrm{~mol}^{-1}\right)$ and $23 \pm 2$ respectively.

\section{Discussion}

Permanganate ion, $\mathrm{MnO}_{4}{ }^{-}$, is a powerful oxidant in an aqueous alkaline medium. As it exhibits many oxidation states, the stoichiometric results and $\mathrm{pH}$ of the reaction media play an important role. Under the prevailing experimental conditions at $\mathrm{pH}>12$, the reduction product of $\mathrm{Mn}(\mathrm{VII})$ is stable and further reduction of $\mathrm{Mn}(\mathrm{VI})$ might be stopped ${ }^{6}$. The Diode Array Rapid Scan Spectrophotometric (DARSS) studies have shown that at $\mathrm{pH}>12$, the product of $\mathrm{Mn}(\mathrm{VII})$ is $\mathrm{Mn}(\mathrm{VI})$ and no further reduction was observed as reported ${ }^{6}$ by Simandi et al. However, on prolonged standing, the green $\mathrm{Mn}(\mathrm{VI})$ is reduced to $\mathrm{Mn}(\mathrm{IV})$ under our experimental conditions.

The permanganate in alkaline medium exhibits various oxidation states, such as $\mathrm{Mn}(\mathrm{VII}), \mathrm{Mn}(\mathrm{V})$ and $\mathrm{Mn}(\mathrm{VI})$. The colour of the solution changed from violet to blue and further to green excluding the accumulation of hypomanganate. The violet colour originates from pink of permanganate and blue from hypomanganate is observed during the course of the reaction. The colour change of $\mathrm{KMnO}_{4}$ solution from violet $\mathrm{Mn}(\mathrm{VII})$ ion to dark green $\mathrm{Mn}(\mathrm{VI})$ ion through blue $\mathrm{Mn}(\mathrm{V})$ ion has been observed.

It is interesting to identify the probable species of ruthenium (III) chloride in alkaline medium. Electronic spectral studies ${ }^{\mathbf{1 4}}$ have confirmed that ruthenium(III) chloride exists in hydrated form as $\left[\mathrm{Ru}\left(\mathrm{H}_{2} \mathrm{O}\right)_{6}\right]^{3+}$. In the present study it is quite probable that the species $\left[\mathrm{Ru}\left(\mathrm{H}_{2} \mathrm{O}\right)_{5} \mathrm{OH}\right]^{2+}$ might assume the general form $\left[\mathrm{Ru}(\mathrm{III})(\mathrm{OH})_{\mathrm{x}}\right]^{3-\mathrm{x}}$. The value of $\mathrm{x}$ would always be less than six because there are no definite reports of any hexahydroxy species of ruthenium. The remainder of the coordination sphere will be filled by water molecule. Hence under the experimental conditions $\left[\mathrm{OH}^{-}\right]>>\left[\mathrm{Ru}^{\mathrm{III}}\right], \mathrm{Ru}^{\mathrm{III}}$ is mostly present as the hydroxylated species $\left[\mathrm{Ru}\left(\mathrm{H}_{2} \mathrm{O}\right)_{5} \mathrm{OH}\right]^{2+}$.

The reaction between permanganate and L-Proline in alkaline medium has a stoichiometry of 1:2 with a first order dependence on the $\left[\mathrm{MnO}_{4}{ }^{-}\right]$and $[\mathrm{Ru}(\mathrm{III})]$ and less than unit order dependence on both the [alkali] and [L-Proline]. No effect of added products such as aldehyde and ammonia was observed.

The results suggest that first alkali combines with permanganate to form an alkali-permanganate species $\left[\mathrm{MnO}_{4} . \mathrm{OH}\right]^{2-}$ in a pre-equilibrium step which explains the less than unit order in alkali. Such type of alkali permanganate species is observed in earlier work ${ }^{25}$. L-Proline in the deprotonated form reacts with ruthenium(III) species to form a complex (C). This complex (C) reacts with alkalipermanganate species in a slow step to form a free radical derived from L-Proline which further reacts with another permanganate species in a fast step to yield the products. The experimental results can be accommodated in Scheme $\mathbf{3}$ as given below.

Spectral evidence for complex formation between catalyst and substrate was obtained from the UV-VIS spectra of the ruthenium (III) species and mixture of ruthenium (III) and L-proline. A bathochromic shift, $\lambda_{\max }$, of ca $6 \mathrm{~nm}$ from 224 to $230 \mathrm{~nm}$ is observed, together with hyperchromicity at $\lambda_{\max } 230 \mathrm{~nm}$.However, the evidence for complex formation is obtained by kinetic studies (i.e., from the Michaelis-Menten plot). The plot of $[\mathrm{Ru}(\mathrm{III})] / \mathrm{k}_{\mathrm{obs}}$ versus $1 /[\mathrm{L}-$ Proline] is linear with an intercept supporting the Ru(III)- L-Proline complex. Such type of substrate-catalyst complex formation has been reported previously ${ }^{26}$. The observed modest enthalpy of activation, relatively low value of the entropy of activation and higher rate constant for the slow step of the mechanism, indicate that oxidation presumably occurs by an inner-sphere mechanism. This conclusion is supported by earlier work ${ }^{27}$. Since scheme $\mathbf{3}$ is in accordance with generally well accepted principle of noncomplementary oxidations taking place in a sequence of one-electron steps, the reaction would involve a radical intermediate. Since permanganate is a one electron oxidant in alkaline medium, the reaction between substrate and oxidant would give rise to a radical intermediate. Free radical scavenging experiment revealed such a possibility. This type of radical intervention in the oxidation of amino acids has also been observed earlier ${ }^{27}$. 

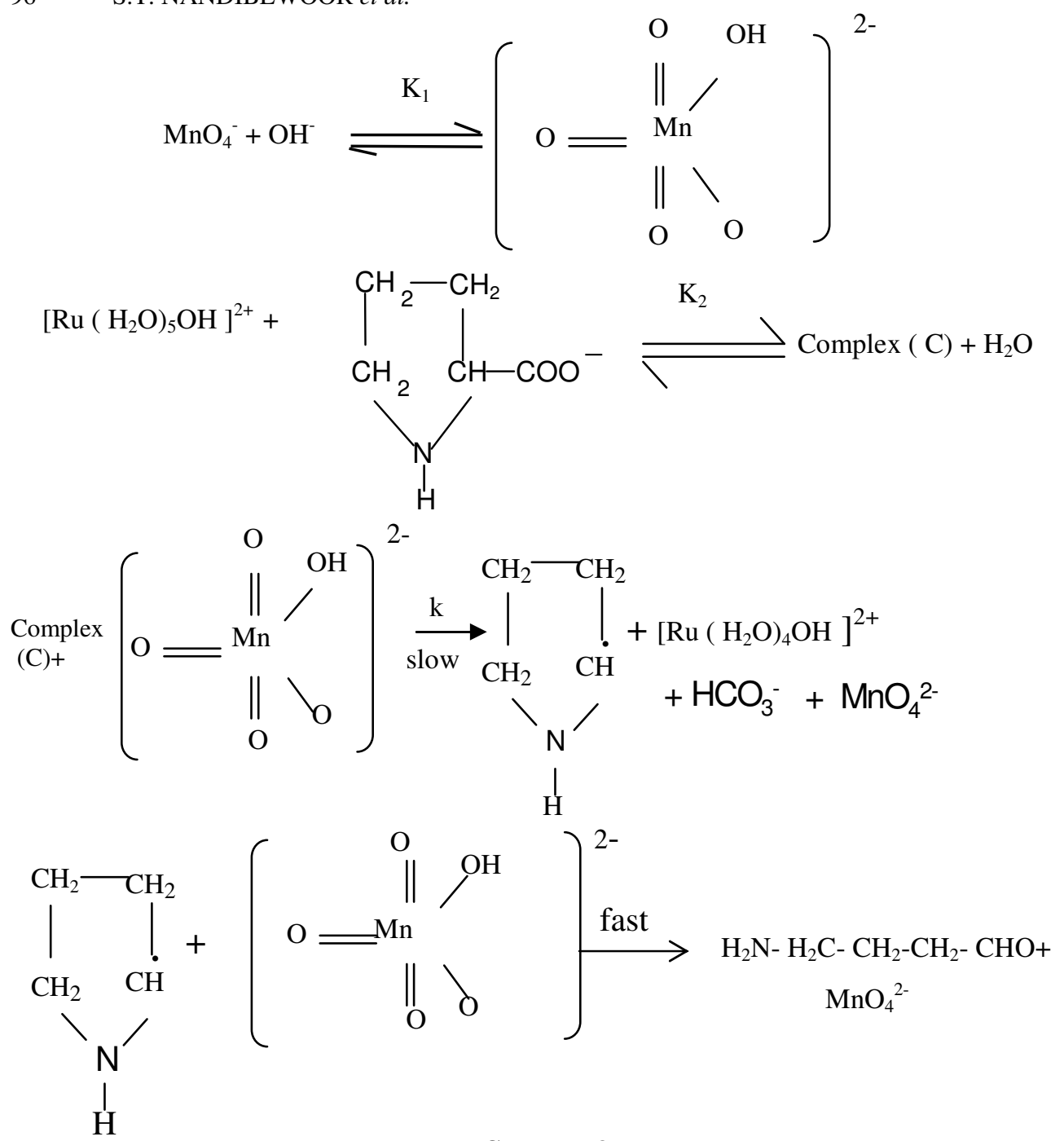

Scheme 3

The probable structure of complex (C) is given as<smiles>CCC1CCCC(C(=O)O[R](O)(O)(O)O)C1CC</smiles>

The thermodynamic quantities for the first equilibrium step in Scheme $\mathbf{3}$ and activation parameters for the limiting step in scheme 3 can be evaluated as follows: The hydroxyl ion 
concentration as in Table1 was varied at four different temperatures and the $\mathrm{K}_{1}$ value was determined at each temperature. The values of $\mathrm{K}_{1}\left(\mathrm{dm}^{3} \mathrm{~mol}^{-1}\right)$ were obtained as 2.3, 4.01, 6.1, and 8.4 at 25, 30, 35 and $40^{\circ} \mathrm{C}$ respectively. A Vant Hoff's plot was made for the variation of $\mathrm{K}_{1}$ with temperature (i.e., $\log$ $\mathrm{K}_{1}$ versus $\left.1 / \mathrm{T}\right)(\mathrm{r}>0.9847, \mathrm{~s} \leq 0.038)$. Similarly the L-Proline concentration as in Table 1 was varied at four different temperature and the $\mathrm{K}_{2}$ value was determined at each temperature. A comparison of these values with those obtained for the slow step of the reaction shows that these values mainly refer to the rate limiting step, supporting the fact that the reaction before the rate determining step is fairly rapid and involves only little activation energy.

Scheme 3 leads to the following rate law (2)

$$
\begin{aligned}
& \frac{\text { Rate }}{\left[\mathrm{MnO}_{4}^{-}\right]}=\mathrm{k}_{\mathrm{obs}}=\frac{\mathrm{kK}_{1} \mathrm{~K}_{2}[\mathrm{~L}-\mathrm{Prolin}][\mathrm{Ru}(\mathrm{III})]\left[\mathrm{OH}^{-}\right]}{1+\mathrm{K}_{1}\left[\mathrm{OH}^{-}\right]+\mathrm{K}_{2}[\mathrm{~L}-\mathrm{Prolin}]+\mathrm{K}_{1} \mathrm{~K}_{2}\left[\mathrm{OH}^{-}\right][\mathrm{L}-\mathrm{Prolin}]} \\
& \frac{\text { rate }}{\left[\mathrm{MnO}_{4}^{-}\right]}-\mathrm{k}_{\mathrm{C}}=\mathrm{k}_{\mathrm{T}}-\mathrm{k}_{\mathrm{U}}=\frac{\mathrm{k} \mathrm{K}_{1} \mathrm{~K}_{2}[\mathrm{~L} \text {-proline }]\left[\mathrm{OH}^{-}\right][\mathrm{Ru}(\mathrm{III})]}{1+\mathrm{K}_{1}\left[\mathrm{OH}^{-}\right]+\mathrm{K}_{2}[\mathrm{~L}-\text { proline }]+\mathrm{K}_{1} \mathrm{~K}_{2}[\mathrm{~L}-\text { proline }]\left[\mathrm{OH}^{-}\right]} \\
& \frac{[\mathrm{Ru}(\mathrm{III})]}{\mathrm{k}_{\mathrm{ob}}}=\frac{1}{\mathrm{k} \mathrm{K}_{1} \mathrm{~K}_{2}[\mathrm{~L}-\mathrm{Pro}]\left[\mathrm{OH}^{-}\right]}+\frac{1}{\mathrm{k} \mathrm{K}_{2}[\mathrm{~L}-\mathrm{Pr}]}+\frac{1}{\mathrm{k} \mathrm{K}_{1}\left[\mathrm{OH}^{-}\right]}+\frac{1}{\mathrm{k}}
\end{aligned}
$$

The terms $\left(1+\mathrm{K}_{1} \mathrm{~K}_{2}\left[\mathrm{OH}^{-}\right][\mathrm{Ru}(\mathrm{III})]\left[\mathrm{MnO}_{4}{ }^{-}\right]\right),\left(1+\mathrm{K}_{1}\left[\mathrm{MnO}_{4}{ }^{-}\right]\right)$and $\left(1+\mathrm{K}_{2}[\mathrm{Ru}(\mathrm{III})]\right)$ also should be in the denominator of equation (2). But in view of low concentrations of $\mathrm{MnO}_{4}{ }^{-}$and ruthenium(III) used, they approximate to unity. Thus the above equation (2) can be rearranged to the following form which is suitable for the verification of the rate law.

According to equation (3), the plots of $[\mathrm{Ru}(\mathrm{III})] / \mathrm{k}_{\mathrm{obs}}$ versus $1 /[\mathrm{L}-\mathrm{asp}](\mathrm{r}>0.9988, \mathrm{~s} \leq 0.045)$ and $[\mathrm{Ru}(\mathrm{III})] / \mathrm{k}_{\mathrm{obs}}$ versus $1 /\left[\mathrm{OH}^{-}\right](\mathrm{r}>0.9913, \mathrm{~s} \leq 0.046)$ should be linear, which is verified in Fig. 3. The slopes and intercepts of the plots lead to the values of $\mathrm{K}_{1}, \mathrm{~K}_{2}$ and $\mathrm{k}$ which were found to be $2.276 \pm 0.16$ $\mathrm{dm}^{3} \cdot \mathrm{mol}^{-1}, 1.67 \pm 0.10 \times 10^{2} \mathrm{dm}^{3} \mathrm{~mol}^{-1}$ and $6.46 \pm 0.24 \times 10^{5} \mathrm{dm}^{3} \cdot \mathrm{mol}^{-1} \mathrm{~s}^{-1}$, respectively. Using these values, the rate constants under different experimental conditions were calculated by equation (2) and compared with experimental data. There is a good agreement between them which supports the Scheme 3. The value of $K_{1}$ is in good agreement with earlier work ${ }^{28}$.

The effect of ionic strength on the rate can be understood essentially on the basis of ionic species as in Scheme 3. The effect of solvent on the reaction kinetics has been described detail in the literature. In the present study the rate determining step involves the reaction between two ions and so equation (4) is applicable:

$$
\ln \mathrm{k}=\ln \mathrm{k}_{\infty}-\mathrm{Z}_{\mathrm{A}} \mathrm{Z}_{\mathrm{B}} \mathrm{e}^{2} / \mathrm{k}_{\mathrm{B}} \mathrm{Tr}_{\mathrm{AB}} \in_{\mathrm{T}}
$$

where $k_{\infty}$ is the rate constant in a medium of infinite dielectric constant, $r_{A B}$ is the sum of the ionic radii and $Z_{A}$ and $Z_{B}$ are the charges on the two ions and $\epsilon_{T}$ is the dielectric constant of the medium. The observed linear plot of $\log \mathrm{k}_{\mathrm{obs}}$ versus $1 / \epsilon_{\mathrm{T}}$ with positive slope is in accordance with equation (4) as $Z_{A}$ and $Z_{B}$ have opposite charges (Scheme 3). The values of $\Delta H^{\#}$ and $\Delta S^{\#}$ were both favourable for electron transfer process. The more negative value of $\Delta S^{\#}$, suggests the complex is more ordered than the reactants.

We have calculated the isokinetic temperature as $220.6 \mathrm{~K}$ for L-Proline and other amino acids studied earlier, $(r \geq 0.957 \& \mathrm{~s} \leq 0.0038)$. The value of $\beta(220.6 \mathrm{~K})$ is lower than experimental temperature $(303 \mathrm{~K})$. This indicates that the rate is being governed by the entropy of activation. 


\section{Catalytic Effect:}

The activation parameters are compared with the uncatalysed reaction ${ }^{17}$. The difference in the activation parameters for the catalysed and uncatalysed reactions, explains the catalytic effect on reaction. The catalyst, ruthenium(III) forms a complex with L-Proline which shows more reducing property than L-Proline itself and hence the catalyst, $\mathrm{Ru}(\mathrm{III})$ lowers the energy of activation.

\section{Conclusion:}

It becomes apparent that in carrying out this reaction the role of $\mathrm{pH}$ in a reaction medium is crucial. It is also noteworthy that under the conditions studied the reaction occurs in two successive one-electron reductions (Scheme 3) rather than two-electron in a single step (Scheme 2). The description of the mechanism is consistent with all the experimental evidence including both kinetic and product studies.

\section{Appendix}

According to Scheme 3,

$$
\begin{aligned}
& \text { Rate }=-\frac{\mathrm{d}\left[\mathrm{MnO}_{4}^{-}\right]}{\mathrm{dt}}=\mathrm{k}[\mathrm{C}]\left[\mathrm{MnO}_{4} \cdot \mathrm{OH}\right]^{2-} \\
& \text { Rate }=\mathrm{k} \mathrm{K}_{1} \mathrm{~K}_{2}[\text { L-proline }]_{\mathrm{f}}\left[\mathrm{MnO}_{4}^{-}\right]_{\mathrm{f}}\left[\mathrm{OH}_{\mathrm{f}}^{-}\right]_{\mathrm{f}}[\mathrm{Ru}(\mathrm{IIII})]_{\mathrm{f}}
\end{aligned}
$$

Total concentration of reductant, [L-Proline $]_{\mathrm{T}}$ is given by, (where the subscripts $\mathrm{T}$ and $\mathrm{f}$ stand for total and free respectively)

$$
\begin{aligned}
{[\mathrm{L}-\text { Proline }]_{\mathrm{T}} } & =[\mathrm{L}-\text { Proline }]_{\mathrm{f}}+[\mathrm{C}] \\
& =[\mathrm{L}-\text { Proline }]_{\mathrm{f}}+\mathrm{K}_{2}[\mathrm{~L}-\text { Proline }]_{\mathrm{f}}[\mathrm{Ru}(\mathrm{III})] \\
{[\mathrm{L}-\text { Proline }]_{\mathrm{T}} } & =[\mathrm{L}-\text { Proline }]_{\mathrm{f}}\left\{1+\mathrm{K}_{2}[\mathrm{Ru}(\mathrm{III})]\right\}
\end{aligned}
$$

Therefore,

$[\mathrm{L}-\text { Proli }]_{\mathrm{T}}$

Similarly,

$$
\begin{array}{cc}
{[\text { L-Proline }]_{\mathrm{f}}} & \frac{}{1+\mathrm{K}_{2}[\mathrm{Ru}(\mathrm{III})]} \\
{\left[\mathrm{MnO}_{4}^{-}\right]_{\mathrm{f}}=} & \frac{\left[\mathrm{MnO}_{4}^{-}\right]_{\mathrm{T}}}{1+\mathrm{K}_{1}\left[\mathrm{OH}^{-}\right]_{\mathrm{f}}} \\
{\left[\mathrm{OH}^{-}\right]_{\mathrm{f}}=} & \frac{\left[\mathrm{OH}^{-}\right]_{\mathrm{T}}}{1+\mathrm{K}_{1}\left[\mathrm{MnO}_{4}^{-}\right]_{\mathrm{f}}}
\end{array}
$$

And

$$
[\mathrm{Ru}(\mathrm{III})]_{\mathrm{f}}=\frac{\mathrm{Ru}(\mathrm{III})]_{\mathrm{T}}}{1+\mathrm{K}_{2}[\mathrm{~L}-\text { Proline }]_{\mathrm{f}}}
$$

Substituting equation (III), (IV), (V) and (VI) in (I), we get

$$
\begin{gathered}
\text { Rate }=-\frac{\mathrm{d}\left[\mathrm{MnO}_{4}^{-}\right]}{\mathrm{dt}} \\
\mathrm{k} \mathrm{K}_{1} \mathrm{~K}_{2}[\mathrm{~L}-\text { Proline }]_{\mathrm{T}}\left[\mathrm{MnO}_{4}^{-}\right]_{\mathrm{T}}[\mathrm{Ru}(\mathrm{III})]_{\mathrm{T}}\left[\mathrm{OH}^{-}\right]_{\mathrm{T}} \\
\left(1+\mathrm{K}_{2}[\text { L-Proline }]\right)\left(1+\mathrm{K}_{2}[\mathrm{Ru}(\mathrm{III})]\right)\left(1+\mathrm{K}_{1}\left[\mathrm{MnO}_{4}^{-}\right]\right)\left(1+\mathrm{K}_{1}\left[\mathrm{OH}^{-}\right]\right)
\end{gathered}
$$


Figure 1. First order plots of aqueous alkaline permanganate oxidation of L-Proline at $25^{\circ} \mathrm{C}$. $\left[\mathrm{MnO}_{4}{ }^{-}\right] \mathrm{x}$ $10^{4}\left(\mathrm{~mol} \mathrm{dm}^{-3}\right)$

Time (min)

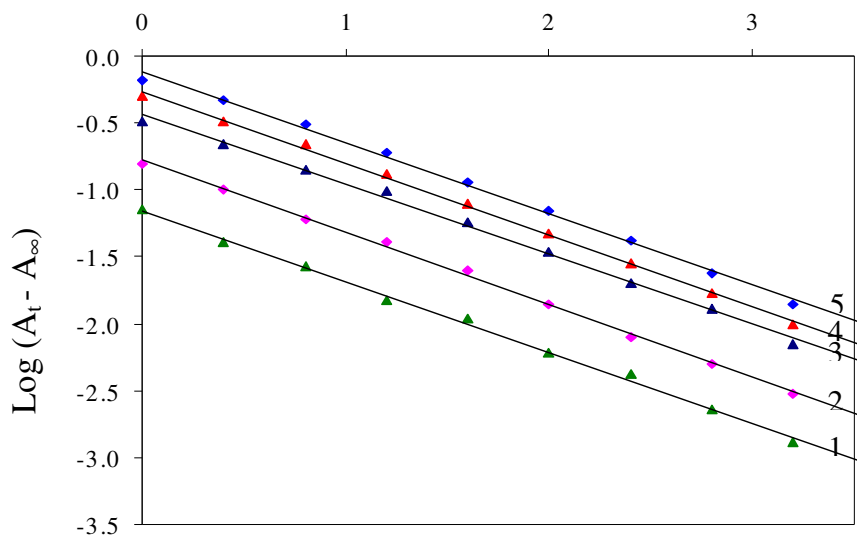
(1) 0.5
(2) 1.0
(3) 2.0
(4) 3.0
(5) 5.0

Figure 2. UV-VIS spectral changes during the oxidation of L-Proline by aqueous alkaline permanganate at $25^{\circ} \mathrm{C}$, catalysed by ruthenium (III).

Scanning time interval $=1 \mathrm{~min}$.
$\left[\mathrm{MnO}_{4}^{-}\right]=2.0 \times 10^{-4} \mathrm{~mol} \mathrm{dm}^{-3}$;
$\left[\mathrm{OH}^{-}\right]=0.1 \mathrm{~mol} \mathrm{dm}^{-3}$;
$[\mathrm{L}-\mathrm{Asp}]=2.0 \times 10^{-3} \mathrm{~mol} \mathrm{dm}^{-3}$;
$[\mathrm{Ru}(\mathrm{III})]=2.0 \times 10^{-6} \mathrm{~mol} \mathrm{dm}^{-3}$;

$\mathrm{I}=0.20 \mathrm{~mol} \mathrm{dm}^{-3}$.

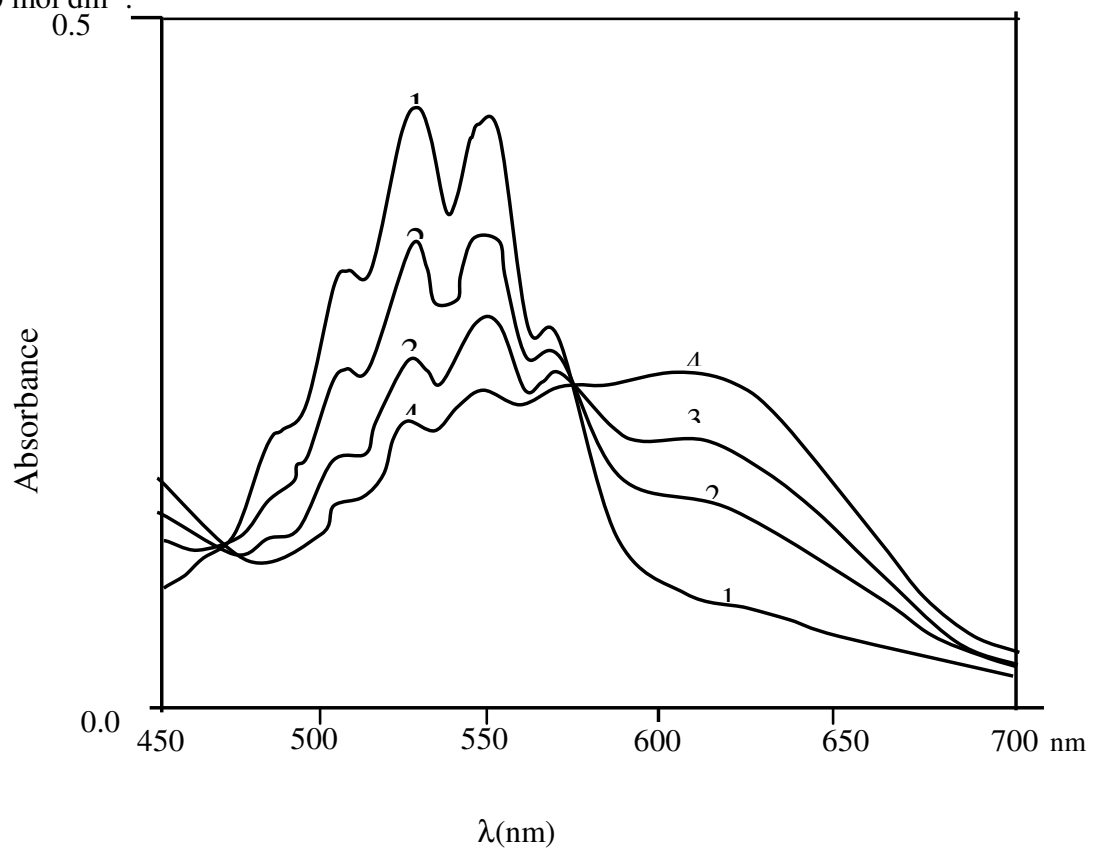


Figure 3. Plot of $[\mathrm{Ru}(\mathrm{III})] / \mathrm{k}_{\mathrm{obs}}$ vs $1 /[\mathrm{L}-\mathrm{Proline}]$ and $[\mathrm{Ru}(\mathrm{III})] / \mathrm{k}_{\mathrm{obs}}$ vs $1 /\left[\mathrm{OH}^{-}\right]$ (conditions as in Table 1).

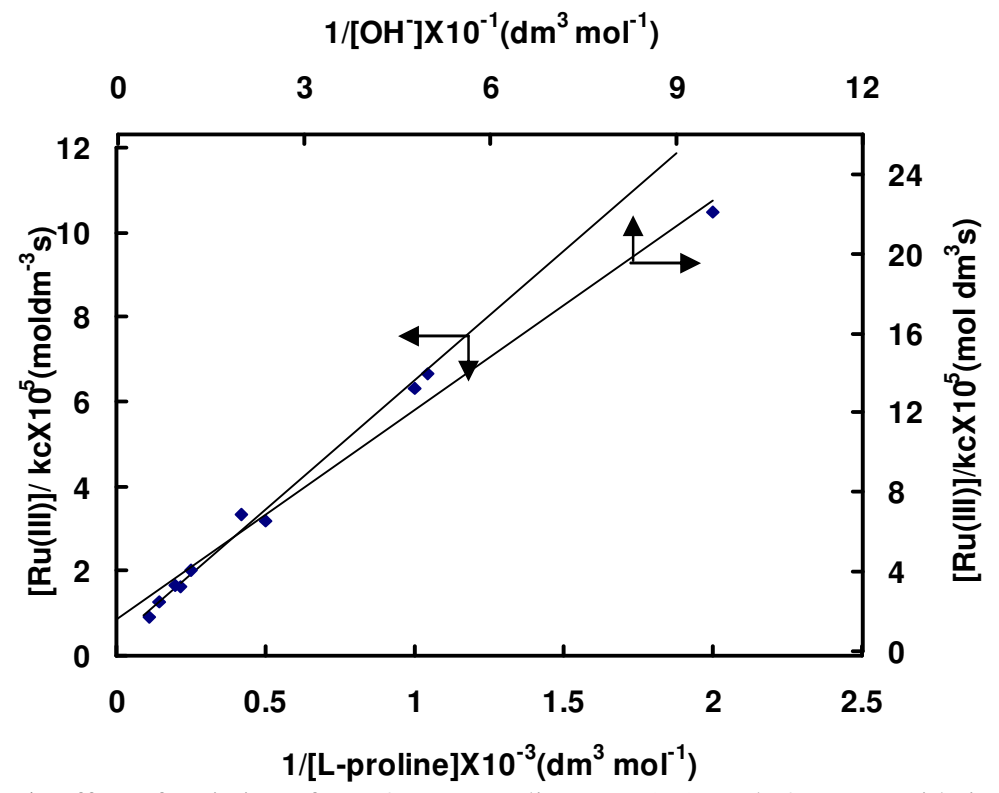

Table 1. Effect of variation of $\left[\mathrm{MnO}_{4}^{-}\right]$, [L-proline], $[\mathrm{Ru}(\mathrm{III})]$ and $\left[\mathrm{OH}^{-}\right]$on oxidation of L-proline by alkaline permanganate at $25^{\circ} \mathrm{C}, \mathrm{I}=0.20 \mathrm{~mol} \mathrm{dm}^{-3}$

\begin{tabular}{cccccccc}
\hline $\begin{array}{c}10^{4}\left[\mathrm{MnO}^{-}\right] \\
\left(\mathrm{mol} \mathrm{dm}^{-3}\right)\end{array}$ & $\begin{array}{c}10^{3}[\mathrm{~L}-\mathrm{pro}] \\
\left(\mathrm{mol} \mathrm{dm}^{-3}\right)\end{array}$ & $\begin{array}{l}10^{6} \mathrm{Ru}(\mathrm{IIII}) \\
\left(\mathrm{mol} \mathrm{dm}^{-3}\right)\end{array}$ & $\begin{array}{l}{\left[\mathrm{OH}^{-}\right]} \\
\left(\mathrm{mol} \mathrm{dm}^{-3}\right)\end{array}$ & $\begin{array}{l}10^{2} \mathrm{k}_{\mathrm{T}} \\
\left(\mathrm{s}^{-1}\right)\end{array}$ & $\begin{array}{l}10^{2} \mathrm{k}_{\mathrm{U}} \\
\left(\mathrm{s}^{-1}\right)\end{array}$ & \multicolumn{2}{c}{$10^{2} \mathrm{k}_{\mathcal{C}}\left(\mathrm{s}^{-1}\right)$} \\
\hline 0.5 & 2.0 & 1.0 & 0.10 & 3.85 & 0.80 & 3.05 & 3.02 \\
1.0 & 2.0 & 1.0 & 0.10 & 3.94 & 0.80 & 3.14 & 3.02 \\
2.0 & 2.0 & 1.0 & 0.10 & 3.91 & 0.80 & 3.11 & 3.02 \\
4.0 & 2.0 & 1.0 & 0.10 & 3.90 & 0.80 & 3.10 & 3.02 \\
5.0 & 2.0 & 1.0 & 0.10 & 3.95 & 0.80 & 3.15 & 3.02 \\
& & & & & & & \\
1.0 & 0.5 & 1.0 & 0.10 & 1.20 & 0.25 & 0.95 & 0.92 \\
1.0 & 1.0 & 1.0 & 0.10 & 2.10 & 0.52 & 1.58 & 1.70 \\
1.0 & 2.0 & 1.0 & 0.10 & 3.91 & 0.80 & 3.11 & 3.02 \\
1.0 & 3.0 & 1.0 & 0.10 & 6.00 & 1.00 & 5.00 & 4.83 \\
1.0 & 5.0 & 1.0 & 0.10 & 7.50 & 1.50 & 6.00 & 5.50 \\
& & & & & & & \\
1.0 & 2.0 & 0.5 & 0.10 & 2.2 & 0.80 & 1.40 & 1.50 \\
1.0 & 2.0 & 1.0 & 0.10 & 3.91 & 0.80 & 3.11 & 3.02 \\
1.0 & 2.0 & 2.0 & 0.10 & 6.70 & 0.80 & 5.90 & 6.03 \\
1.0 & 2.0 & 3.0 & 0.10 & 9.80 & 0.80 & 9.00 & 9.05 \\
1.0 & 2.0 & 5.0 & 0.10 & 14.8 & 0.80 & 14.0 & 15.1 \\
& & & & & & & \\
1.0 & 2.0 & 1.0 & 0.02 & 0.85 & 0.15 & 0.70 & 0.71 \\
1.0 & 2.0 & 1.0 & 0.05 & 2.00 & 0.55 & 1.45 & 1.66 \\
1.0 & 2.0 & 1.0 & 0.10 & 3.91 & 0.80 & 3.11 & 3.02 \\
1.0 & 2.0 & 1.0 & 0.15 & 5.00 & 0.97 & 4.63 & 4.75 \\
1.0 & 2.0 & & 0.20 & 7.00 & 1.02 & 5.20 & 5.10 \\
\hline
\end{tabular}




\section{References}

1 Stewart R, Oxidation in Organic Chemistry (Part A Ed. K.B. Wiberg, Ch.1 Academic Press, New York) 1965.

2 Simandi L I, The Chemistry of functional groups, Ed. S. Patai, Z.Rappoport, Ch.13 (Wiley, Chichester. Suppl. C) 1983.

3 Lee D G, Lee E J and Brown K C, Phase Transfer Catalysis, new chemistry, catalysts and applications.(ACS symposium series No.326, American Chemical Society, Washington D C) 1987,p.82.

4 Perez-Benito J F and Lee D G, J. Org. Chem., 1987,52, 3239.

5 Gardner K A,. Kuehnert L L and Mayer J M, Inorg. Chem.1997, 36, 2069.

6 Bilehal D C, Kulkarni R M and Nandibewoor S T, Z. Phys. Chem. 2003. 1, 217,

7 Kawle B, Thirupathi Rao M and Adininarayana M, Indian J.Chem. 1996, 35A, 667 .

8 Cooper A J L, Ginos J Z and Meister A, Chem. Revs. 1983. 83, 321.

9 Clarke T G, Hampson N A, Lee J B , Morely J R and Scanlon B, J. Chem. Soc. 1970,815.

10 Simandi L I, Jaky M, Savage C R and Schelly Z A, J. Am. Chem. Soc. 1985,107,4220; Timmanagoudar P L, Hiremath G A and Nandibewoor S T, Transition. Met. Chem.1997, 21, 193.

11 Adininarayana M, Sethuram B and Navneeth Rao T, J. Indian Chem. Soc. 1976, 53, 877.

12 Mahanti M K and Laloo D, J. Chem. Soc. Dalton. Trans. 1990, 311.

13 Senagar S K S and Yadav B S, J. Indian Chem. Soc, 1988, 65, 88; Senagar S K S and Yadav B S, J. Natl. Appl. Sci. Bull. 1987,39,179.

14 Singh H S, Singh R K, Singh S M and Sisodia K, J. Phys. Chem., 1977, 81, 1044; Nandibewoor S T, Hiremath G A and Timmanagoudar P L, Transition. Met. Chem.2000, 25, 394.

Bailar J C, Emeleus H J, and Sir Donald Nyholm ; Trotman-Dickenson,A.F. (Eds), Comprehensive Inorganic Chemistry, (Pergamon press, Oxford) 1975, 3, p.810. Sykes A G, Advances in Inorganic and Radio Chemistry, Ed. Gemeleus H.; Sharpe A G, 1967,10, p. 153 ..

17 Mahesh, R T, Bellakki M B and Nandibewoor S T, J.Chem.Res. 2002 (In press)

18 Jeffery G H, Bassett J, Mendham J and Denney R C, Vogel's text book of Quantitative Chemical Analysis, $5^{\text {th }}$ edn, (ELBS Longman, Essex, UK) 1996, p.371.

19 Carrington A, Symons M C R, J. Chem. Soc. 1956, 3373.

20 Reddy C S, and Vijaykumar T, Indian J. Chem. 1995, 34A, 615.

21 Feigl F, Spot Tests in Organic Analysis; Elsevier: New York, 1975, 333.

22 Bellamy L J, The Infrared Spectra of Complex Molecules; Methuen and Co.Ltd; London, 1958, 162.

23 Lide D R, (ed) CRC Hand Book of chemistry and physics, $73^{\text {rd }}$ edn (CRC press, Inc, London) 1993,p.8-51.

24 Kolthoff I M, Meehan E J and Carr E M, J. Am. Chem. Soc,. 1953, 75, 1439; Bhattacharya S and Banerjee P, Bull. Chem. Soc. Jpn. 1996, 69, 3475.

25 Halligudi N N, Desai S M and Nandibewoor S T, Transition. Met. Chem. 1999 26, 28; Vivekananda S, Santappa M and Shanmuganathan S P, Indian J.Chem. 1983, 22A, 244.

26 Rao S V and Jagannadham V, React. Kinet. Catal. Letts. 1985, 27, 239; Morab V A and Nandibewoor S T, React. Kinet. Catal. Letts. 1994,53, 25.

27 Halligudi N N, Desai S M and Nandibewoor S T, Int. J. Chem. Kinet. 1999, 31, 789; Moore F M and Hicks K W, Inorg. Chem. 1975, 14, 413; Hicks K W, J. Inorg. Nucl. Chem. 1976, 38, 1381.

Bilehal D C, Kulkarni R M and Nandibewoor S T, Can. J. Chem. 2001, 79, 1926. 


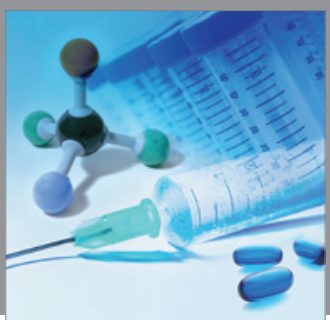

International Journal of

Medicinal Chemistry

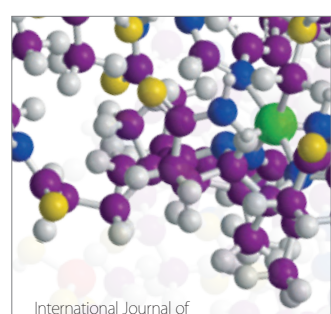

Carbohydrate Chemistry

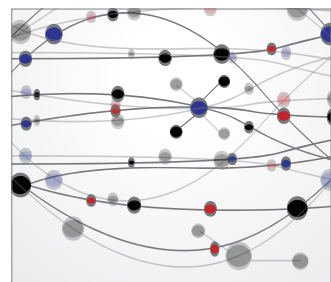

The Scientific World Journal
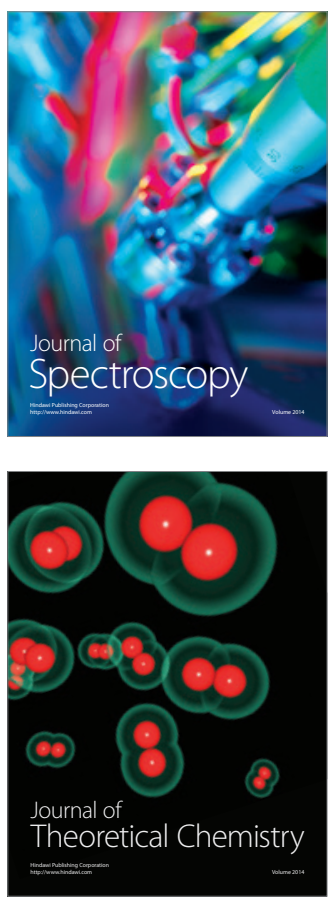
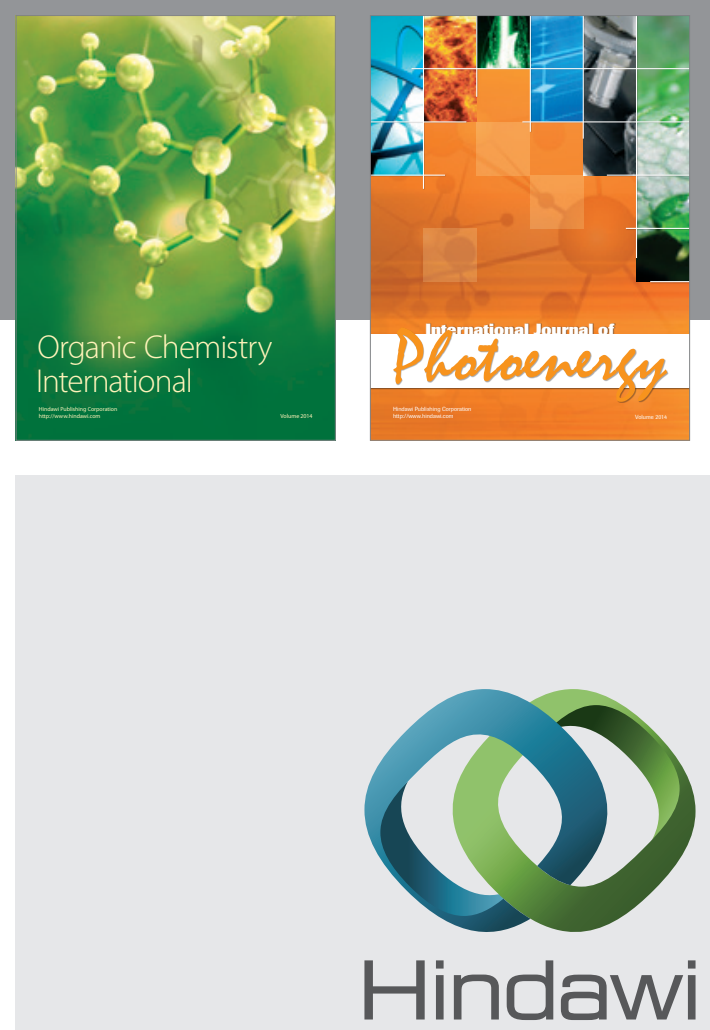

Submit your manuscripts at

http://www.hindawi.com
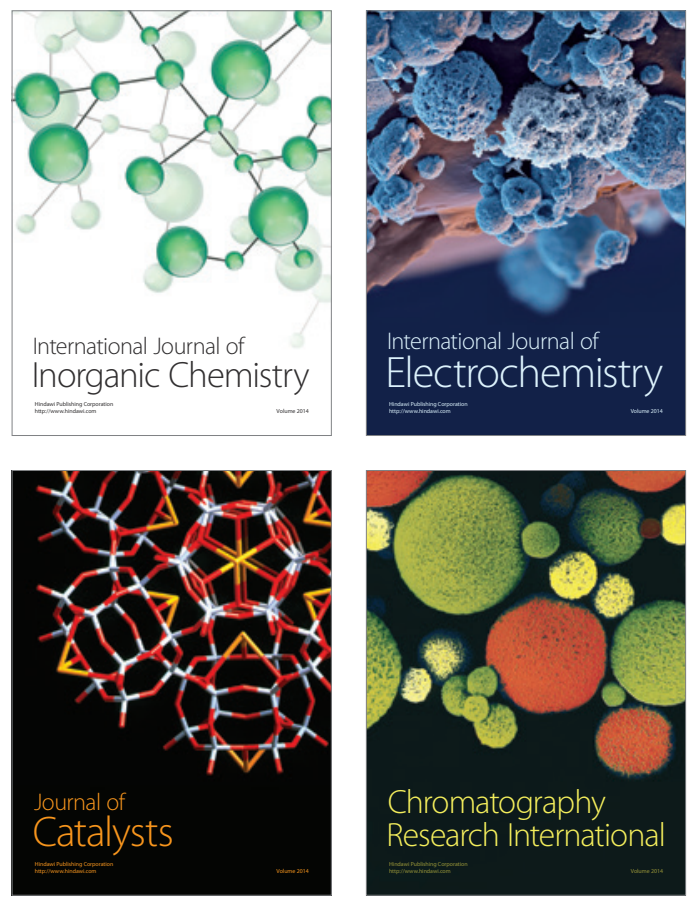
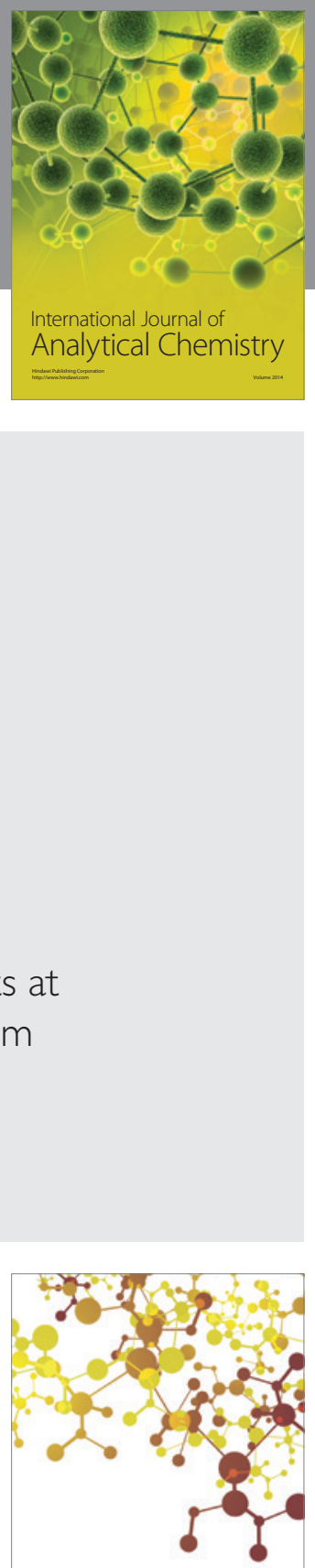

Journal of

Applied Chemistry
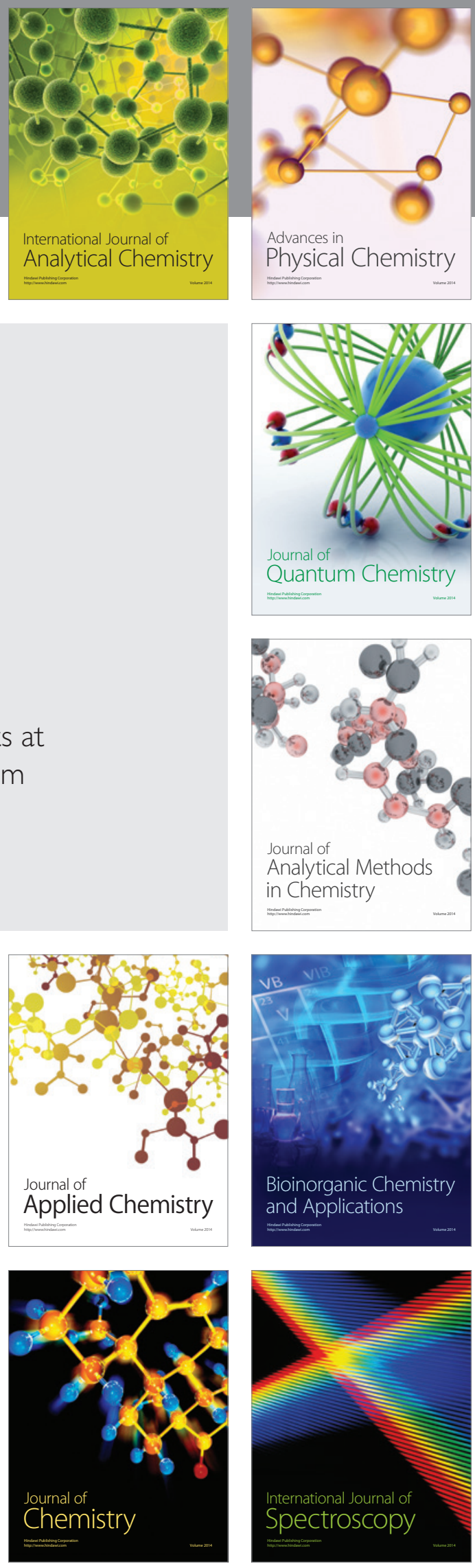